\title{
Modelos de feminidad de los años cuarenta: Ingenuas y pitucas en el intercambio cinematográfico Argentina-España
}

\author{
Femininity Models in the Forties: Ingenuas and Pitucas \\ in the Film Exchange Between Argentina and Spain
}

\author{
Emeterio Diez Puertas \\ ORCID iD: https://orcid.org/0000-0002-2206-0480 \\ Universidad Camilo José Cela, Madrid, España
}

En la década de 1940, en un periodo de aislamiento internacional, Argentina y España coincidieron en intercambiarse un número importante de comedias sentimentales. En ellas podía observarse dos modelos de feminidad: la ingenua y la pituca. Ambos estereotipos eran adaptaciones hispanas de modelos narrativos hollywoodienses. El intercambio se hacía en virtud de la política autárquica española que era, a la vez, un control de la balanza de pagos y, en principio, una garantía del contenido de las películas, pues lo importado y lo exportado provenía de países afines por cultura, tradición o ideología.

Palabras Clave: Argentina; España; Franquismo; Hispanidad; Cine; Género.

In the 1940s, in a period of international isolation, Argentina and Spain coincided in exchanging a significant number of sentimental comedies. Two models of femininity could be seen in them: the ingenua and the pituca. Both stereotypes were Hispanic adaptations of Hollywood narrative models. The exchange took place under the Spanish autarchic policy. It controlled the balance of payments and, in principle, guarantee of content of the movies, since what was imported and exported came from countries related by culture, tradition or ideology.

KeYwords: Argentina; Spain; Francoism; Hispanidad; Cinema; Gender.

Copyright: (C) 2021 CSIC. Este es un artículo de acceso abierto distribuido bajo los términos de la licencia de uso y distribución Creative Commons Reconocimiento 4.0 Internacional (CC BY 4.0). 


\title{
Introducción
}

El objeto de estas páginas es estudiar la recepción de dos estereotipos o máscaras femeninas presentes en el cine español y en el cine argentino de los años cuarenta y que tienen por cronotopo el primer amor. Nos referimos a las máscaras de la ingenua y la pituca e, implícitamente, a sus partenaires masculinos. En su obra Tipos psicológicos, Jung habla de la «máscara» así:

\begin{abstract}
Mediante su identificación más o menos completa con la actitud adoptada en cada caso el individuo engaña cuando menos a los demás, y a menudo se engaña también a sí mismo, en lo que respecta a su carácter real; se pone una máscara, de la que sabe que corresponde, de un lado, a sus intenciones, y, de otro, a las exigencias y opiniones de su ambiente; y en ello unas veces prepondera un elemento y otras el otro. A esa máscara, a esa actitud adoptada — ad hoc — yo la llamo persona. Con ese término se designaba la máscara que en la Antigüedad llevaban puesta los actores teatrales. ${ }^{1}$
\end{abstract}

La palabra «ingenua» viene del latín ingenuus y designa la persona nacida libre y, por extensión, sería la máscara de la persona de carácter noble. «Pituca» se usa en Hispanoamérica para designar a una persona presumida y, en otros casos, de clase alta. En Argentina, la palabra viene de los inmigrantes rusos. Su término pituj significa gallo y, en sentido figurado, se usa para designar la máscara de una persona arrogante, cursi o bien una persona extravagante en la forma de vestir y modales.

Argentina y España se intercambiaron películas con estos personajes entre 1944 y 1955 en virtud de sus acuerdos de importación y exportación de películas. Ahora bien, dado que el franquismo decidía mediante la censura y los acuerdos comerciales qué tipo de cine extranjero entraba en España, ${ }^{2}$ la presencia de estas dos máscaras solo era posible si el régimen entendía que el modelo de femineidad del cine argentino se ajustaba a los principios del Movimiento. ${ }^{3}$ Hay que recordar el carácter antifeminista de la dictadura franquista. Un antifeminismo que le llevó a reprimir con violencia y dureza aquel modelo de mujer que se alejaba del defendido por el régimen. ${ }^{4}$ De hecho, vamos a demostrar que España estrena más cine argentino de ingenuas que de pitucas precisamente porque la primera es, a los ojos del régimen, más «femenina». Es más, también España exporta a

1 Jung, 2013 [1921], 758.

2 Diez Puertas, 2002.

3 Richmond, 2004. Folguera Crespo, 1997.

4 Cobo Romero y Ortega López, 2014. 
la Argentina películas protagonizadas por pitucas, mujeres que provocan la risa simplemente porque su insólita libertad se ve como una extravagancia.

Por otro lado, es importante entender que estas máscaras, aunque provienen de la comedia cinematográfica norteamericana, ${ }^{5}$ adquieren una forma «nacional» en virtud del trabajo de una serie de escritores y guionistas. Nos referimos a Wenceslao Fernández Flórez, los hermanos Álvarez Quintero, Carlos Arniches, Luisa-María Linares, Carmen de Icaza o, desde el otro lado del Atlántico, Sixto Pondal Ríos, Carlos Olivari, Carlos Adén o Manuel Romero. Es más, la aportación de Gregorio Martínez Sierra, exilado en Buenos Aires, y la presencia en el cine argentino de una serie de actores españoles, como Ernesto Vilches, dan también a estas comedias un toque hispano. En este sentido, el artículo ilustra la labor intelectual de los españoles en la Argentina, una colonia formada por alrededor de 750.000 personas, ${ }^{6}$ las cuales son los espectadores más fervientes del cine español que llega al país.

En fin, el cine que vamos a examinar entra y sale de España en un contexto histórico muy concreto. La Argentina se ha convertido en el país extranjero más importante para Franco por su negativa a participar del aislamiento internacional del régimen y por abastecerla del trigo necesario para paliar el hambre. ${ }^{7}$ El intercambio de películas, en otras palabras, forma parte de una geopolítica alternativa al panamericanismo y a la política de bloques de la Guerra Fría. Franquismo y peronismo coinciden en que el cine es una herramienta de la comunicación política y un poder «blando» ${ }^{8}$ en la construcción de la Hispanidad. ${ }^{9}$ Bien es cierto que buena parte del cine argentino que llega es de producción previa al golpe de 1943 y a la proclamación de Perón como presidente en las elecciones democráticas de 1946. Pero Perón está metido en asuntos de cine desde 1944 a través de la Secretaría de Trabajo. ${ }^{10}$ Es desempeñando este puesto cuando conoce a la actriz Eva Duarte. $\mathrm{Y}$ es desde ese puesto cuando favorece una política cinematográfica proteccionista que le enfrenta con Hollywood y Washington. Estados Unidos impide que la Argentina tenga película virgen para tirar copias destinadas a la exportación de sus filmes más recientes, de ahí que la política peronista conduzca a que lleguen a España películas rodadas antes del peronismo.

5 Echart Orus, 2005.

6 Ortuño Martínez, 2012. Saura, 2013.

7 Figallo, 1992. González de Oleaga, 2001.

8 Nye, 2004.

9 González Calleja, 1988. Delgado Gómez-Escalonilla, 1992.

10 Kriger, 2009. 


\section{La comedia blanca y el cronotopo del primer amor}

Las películas argentinas pasan a formar parte de forma regular de la programación de las salas de cine españolas desde la llegada del cine sonoro. Aunque su cuota de mercado es pequeña, alrededor del $6 \%$, el cine argentino consigue algunos éxitos relevantes. Son títulos que, además, originan una corriente de importación de producciones similares, es decir, películas de tangos, melodramas y comedias. Durante la primera fase del periodo que aquí vamos a estudiar, estos tres géneros se mantienen, pero con una suerte desigual. En concreto, la alta presencia de comedias blancas constituye una de las notas características del cine argentino visto en España.

La comedia blanca es una comedia romántica donde el humor deriva de la torpeza sentimental de los personajes para alcanzar el idilio del amor. Alejandro Kelly Hopfenblatt ha estudiado ampliamente el catálogo de títulos. Las de mayor éxito en Madrid son Su primer baile (1942), Siete mujeres (1944) y Dama de compañía (1940). El género también se conoce como comedia sentimental burguesa o comedia rosa. Se trata de una forma emocional del relato muy extendida en todas las cinematografías. De hecho, la ingenua y la pituca son adaptaciones nacionales de convenciones narrativas estadounidenses. ${ }^{11}$

La mayoría de las películas que de este modelo llegan a España fueron rodadas entre 1941 y 1943 por Lumiton y Argentina Sono Film (ASF). Su singularidad estriba en que es una comedia construida sobre un idilio amoroso protagonizado por una mujer definida con el rasgo psicológico de «la ingenua». En realidad, ya en diciembre de 1942 se había estrenado en España un ejemplo del cine de ingenuas, Soñar no cuesta nada (1941), la cual tuvo buen éxito. Ahora bien, también tuvieron impacto en España un pequeño número de títulos argentinos que, dentro de la misma clave de género, mostraban un modelo de mujer opuesto a la ingenua y, por eso mismo, tuvieron encontronazos con la censura. Nos referimos a la pituca. $M i$ amor eres tú (1941) es el título estrenado en España que mejor retrata este otro modelo: la joven rica, moderna y alocada que con tanto talento encarna Paulina Singerman.

11 Hollywood da forma a Deanna Durbin, la ingenua más internacional, y también a la niña rica y caprichosa que Claudette Colbert interpreta en It Happened One Night (1934). Pero, como decíamos, esto no quiere decir que la comedia rosa argentina carezca de originalidad. Al contrario, tomando modelos hollywoodienses, los dota de una personalidad propia de indudable interés y hasta algún título argentino tiene su adaptación en Estados Unidos. 
En cualquier caso, ambos personajes, la ingenua y la pituca, coinciden en que protagonizan una trama basada en el cronotopo del idilio del primer amor. Empleamos la expresión idilio para señalar que este tipo de relatos pertenece a una categoría clasificatoria de nivel superior: las narraciones que comienzan reflejando un mundo ordenado y perfecto, pero, de pronto, algo importante se destruye, si bien a lo largo de la trama todo se resuelve y se impone el final feliz o idílico. Dependiendo de si lo que se destruye son las relaciones familiares, las amorosas, las laborales o con la naturaleza, el cronotopo idílico adopta cuatro formas fundamentales: el idilio familiar, el idilio amoroso, el idilio del trabajo artesanal y el idilio del trabajo agrícola. ${ }^{12}$ Mediante el uso de tramas y subtramas estos cronotopos pueden combinarse entre sí, de modo que, por ejemplo, una mujer afronte conseguir el idilio amoroso y el del trabajo o bien un padre busque el idilio familiar mientras la hija busca el idilio amoroso. En casi todos los casos, el cronotopo idílico adopta la forma de un relato realista. La acción sucede en un universo espacial limitado característico: el salón burgués, el salón de baile, el taller, la casa en el campo. El tiempo es el del ciclo de la vida y, por lo tanto, el de los ritos de paso. Asistimos a nacimientos y muertes, al primer beso y a la boda, al primer empleo y a la jubilación, al cultivo de la semilla y a la cosecha. De hecho, un relato puede concentrase en un espacio-tiempo concreto de este desarrollo. Entonces podemos distinguir un cronotopo de nivel inferior. El idilio del amor, por ejemplo, puede manifestarse en el cronotopo del primer amor, que es el que aquí nos ocupa, o en el cronotopo del matrimonio. En todos los casos, el resultado es un texto alejado de la realidad, evasivo, en el que la familia, la pareja, la empresa y la tierra salen ennoblecidas y embellecidas, esto es, ajustadas al imaginario social impuesto por el modelo ideológico imperante.

De todos los cronotopos, el amoroso suele ser, aparentemente, el más evasivo, pues, aunque se expresa como drama, melodrama y hasta thriller, suele emplear un tono de comedia en distintas formas, dependiendo de si busca la carcajada o la sonrisa. Están la comedia cómica, la sofisticada, la dramática, la fantasía romántica... Hollywood con su producción suele determinar qué forma emocional adopta el idilio amoroso en cada momento histórico.

12 Bajtin, 1989 [1975], 375 y ss. 


\section{La máscara de la ingenua: la femineidad angelical}

Di Núbila considera que Los martes, orquídeas (1941) es el título fundador del cine de ingenuas, pues la actriz que hace este papel, Mirtha Legrand, que entonces tenía unos catorce años, se convierte en el prototipo del personaje. La ingenua — dice Di Núbila — es una adolescente virginal, frágil y hermosa, viva imagen de la eterna ilusión del primer amor. Pero Di Núbila afirma también que Sixto Pondal Ríos y Carlos Olivari escriben el argumento de Los martes, orquídeas pensando en Delia Garcés, si bien no se pudo contar con ella. Delia Garcés había interpretado un año antes Dama de compañía. ${ }^{13}$ Claudio España sostiene que este filme es, en realidad, la primera película en la que echa a andar la comedia blanca y la que abre paso a la ingenua. ${ }^{14}$ También es la primera que llega a Madrid en este periodo.

Es decir, el modelo narrativo, en lo que tiene de singular dentro del cine argentino, lo crean los dos guionistas de Dama de compañía: el español Gregorio Martínez Sierra y Carlos Adén, seudónimo de Luis de Elizalde. Claro que esta «creación» tiene numerosos precedentes. Por eso Primer Plano la describe como: «Asunto de novela rosa, en el que la cinta se desliza sin que el espectador llegue a aburrirse del todo porque se encuentra con una cierta dinámica en la manera de conducir las situaciones que llega a hacer olvidar lo vulgar y usado del asunto». ${ }^{15}$ Lo que Martínez Sierra y Adén consolidan con Dama de compañía es una situación dramática que, con sus variantes, caracteriza buena parte de los títulos posteriores, sobre todo, los que se ven en España. La situación inicial nos presenta a una madre viuda (aquí Elsa O’Connor) que vive rodeada de tres hijas de distintas edades, dos de ellas casaderas. Entre todas destaca por su ingenuidad e inocencia Isabel (Delia Garcés). El hogar está a cargo de una especie de mentor, aquí una gobernanta llamada Petrona (Olinda Bozán, actriz que encabeza el reparto). La gobernanta se ocupa del día a día de la casa y está pendiente del corazón de todas ellas, pues hasta la madre despierta de nuevo al amor, se hace adolescente, y aspira a casarse con su pretendiente oculto, un famoso pianista (Esteban Serrador) al que ha conocido en un viaje. Pero la ingenua y el pianista se enamoran sin saber el vínculo con la madre. El enredo se resuelve cuando la madre renuncia al amor del pianista, de modo que la ingenua se casará permaneciendo ajena a este sacrificio.

13 Di Núbila, 1959, 159-161.

14 España y Rosado, 1984, 171.

15 Gómez Tello, José Luis, «Dama de compañía», Primer Plano, Madrid, 25 de marzo de 1944, s. p. 
De hecho, Martínez Sierra (en realidad, su primera mujer, María Lejárraga) había sido el autor de otro precedente, Canción de cuna, una obra de teatro escrita en 1911. Bien es cierto que la pieza estaba más cerca del melodrama o era una comedia dramática. Hollywood la había llevado al cine en 1933 y ahora Martínez Sierra estaba rodando una segunda versión en Buenos Aires. La acogida por la crítica argentina de Canción de cuna (1941) es muy buena. Se habla de una película que hace sonreír con simpatía y llorar dulcemente. A España llega muy tarde, en 1947, por estar prohibida toda la obra de Martínez Sierra. Cuando este regresa del exilio y se levanta dicha prohibición, Primer Plano publica una crítica negativa, casi vengativa del estreno: lenta, mal interpretada y demasiado teatralizada. «Nada ha ganado el cine argentino con la nueva versión». ${ }^{16}$ Sin embargo, es una de las pocas películas argentinas que Franco ve en su sala del Palacio del Pardo.

En concreto, en el cine argentino, el cronotopo del primer amor desde el punto de vista de la ingenua presenta las siguientes características narrativas:

1. El tema es el primer amor, que ya es el amor definitivo.

2. Este tema se expresa de una forma cómica y sentimental. Pero son formas que nacen del carácter de la ingenua y, por lo tanto, lo cómico busca la sonrisa, el humor tierno y los toques poéticos mientras lo amoroso resalta lo puro, lo inocente, lo romántico y busca que lleve al espectador a la lágrima. Son unos rasgos que conducen a que esta clase de películas sean acusadas de sensibleras y empalagosas.

3. La fábula se articula sobre la meta del idilio amoroso. Se trata de logar el amor sexual sin que el sexo, salvo el beso fugaz, se exprese y sin que la tensión que crea con la madre o las hermanas implique perder el amor familiar. Al contrario, se trata de extenderlo y perpetuarlo.

4. El reparto está lleno de mujeres que representan las distintas edades (vejez, madurez, adolescencia y niñez) y los títulos de crédito los encabeza la actriz adolescente que interpreta el personaje de la ingenua. Así se denomina a una joven bonita, angelical, tierna, candorosa y virgen. Las ingenuas suelen ser Delia Garcés, María Duval y, sobre todo, las gemelas Mirtha y Silvia Legrand, de modo que ellas dos proporcionan la fisonomía más característica de la ingenua.

5. El espacio más importante es el hogar. En algún caso, un centro educativo donde los sexos están segregados. El hogar suele estar roto o incompleto. Normalmente porque falta la figura paterna y la madre es

16 Gómez Tello, José Luis, «Canción de cuna», Primer Plano, 5 de noviembre de 1947, s. p. 
incapaz de llevar la casa. El rol de padre debe asumirlo, en ocasiones, un mentor o anciano de sexo masculino o femenino que desempeña el papel de gobernanta, mayordomo, jardinero, abuelo... En ese hogar, casi nunca falta un piano que la ingenua toca o bien su amor es un pianista. En ambos casos, el piano es símbolo de refinamiento y la música melancólica y romántica que se interpreta retrata la psicología del personaje.

6. El tiempo está ligado a la adolescencia. Los propios títulos remiten a ese momento sentimental: Dieciséis años, Adolescencia, Su primer baile, El tercer beso, Los martes, orquídeas, Soñar no cuesta nada o bien Cuando florezca el naranjo. A esta última, su guionista, el español Alejandro Casona, incorpora la nota personal de lo onírico mediante un sueño de la protagonista.

Si el franquismo admite en su mercado tantos filmes con estas características es porque el cine de las ingenuas consolida su visión patriarcal de la mujer. De hecho, este tipo de películas solo tiene problemas con la censura franquista en las contadas veces en que aparece algo sexual. Bien es cierto que la censura de la Iglesia clasifica muchas de ellas para mayores de 21 años, es decir, las prohíbe para las espectadoras que están en la edad de las «ingenuas». El caso más problemático es Dama de compañía, pues se exhibe el cuerpo femenino, abundan los besos de pasión y el humor da entrada a lo picante. En este sentido, la censura del Estado impone ocho cortes: una muchacha en combinación, otra jabonándose en una bañera, unos besos, una escena en la que Petrona se sienta a ordeñar una vaca, pero resulta que descubre sonrojada que es un toro y dos frases, «Dame tu boca» $\mathrm{y}$ «Dejar que luego obre la naturaleza». ${ }^{17}$ Con estos cortes, el franquismo mete la película en cintura, es decir, la ajusta al molde del cine de ingenuas.

Siete mujeres, de Benito Perojo, es la tercera película del modelo que se estrena en España. Se presenta en Madrid el 12 marzo de 1945 en el cine Rialto y su éxito hace que esté en cartel dos semanas. Pero la crítica la ve de otra manera. Miguel Ródenas en $A B C$ dice que es cine malo, lleno de vulgaridades, tópicos, adocenada, ñoña, ridícula en su insistencia en los constantes abrazos de los personajes..$^{18}$ Primer Plano afirma que Perojo no ha sabido superar el punto de partida teatral del argumento con dinamismo

17 Dama de compañía, 3 de marzo de 1944, Archivo General de la Administración, Alcalá de Henares (AGA), c. 36/03191.

18 Ródenas, Miguel, «Siete mujeres», ABC, Madrid, 13 de marzo de 1945, 21. 
cinematográfico, aunque destaca el trabajo de Silvia Legrand. Con partida teatral se refiere a que la película está basada en un tema español, pues es una adaptación de una comedia de Leandro Navarro y Adolfo Torrado que había tenido un gran éxito en España en 1940. Esto demuestra, como habíamos señalado, que el modelo tiene numerosos antecedentes y algunos son españoles.

En 1946, se estrenan en Madrid tres títulos más, con lo que el impacto de la máscara ya es evidente. De Los martes, orquídeas la crítica española dice que es una «comedia amable, sencilla, sin pretensiones y que distrae». ${ }^{19}$ En cuanto a Dieciséis años (1943), vuelve a cumplir al dictado el modelo narrativo ya descrito, pues, aunque aquí la ingenua no tiene un primer amor, la madre se infantiliza y siente algo parecido cuando un famoso pianista francés la corteja. Esta repetición hace que Primer Plano diga que es un argumento ya gastado, dirigido sin nervio por Christensen, aunque con excelentes interpretaciones. ${ }^{20}$

El tercer título estrenado en 1946 es Su primer baile, el éxito más grande del modelo en España por los días en cartel y las buenas críticas. Está 14 días en la sala Vergara, el doble de lo normal, pero en sesión continua con una película de terror norteamericana. Miguel Ródenas en $A B C$ dice que la película podría haberse exhibido sin desdoro en los locales de estreno de la Gran Vía, alaba el trabajo de Ernesto Vilches y comienza su crítica diciendo:

Ya tiene la Argentina, además de su arrolladora simpatía, su hispanidad, su trigo y un Gobierno flamante, esa muchachita, «estrella» del cinematógrafo porteño que se llama María Duval, con juventud y aquilatadas cualidades artísticas suficientes para poder codearse sin menoscabo, con la propia Diana Durbin. Esta afirmación no es hiperbólica, puesto que también se trata de una adolescente llena de ternura, ingenuidad y sencillez que ante la cámara sabe muy bien dónde la aprieta el zapato. Conoce la «pose» ante el objetivo y da a sus intervenciones un aire pacato sin gazmoñerías ni artificios inútiles $[\ldots]$ con su buen arte defiende un asunto trillado [...] dándole novedad, interés y gracia ingenua. ${ }^{21}$

Primer Plano en la crítica de Su primer baile ya identifica un corpus. Habla de la presencia de una forma narrativa que describe como «comedia en blanco»: historias de amor que sin grandes pasajes oscuros desembocan en un final feliz. «Su construcción obedece a líneas sencillas, con unos

19 Gómez Tello, José Luis, «Los martes, orquídeas», Primer Plano, 14 de marzo de 1946, s. p.

20 Gómez Tello, José Luis, «Dieciséis años», Primer Plano, 1 de septiembre de 1946, s. p.

21 Ródenas, Miguel, «Su primer baile», ABC, 12 de junio de 1946, 28. 
toques de sombra que contrapesan acertadamente lo liso de su relato». También identifica a una de las ingenuas, María Duval, que se descubre para el crítico como «una actriz de arte delicado y de fino matiz». ${ }^{22}$

El cine de ingenuas tiene que ver con lo que Bettelheim ${ }^{23}$ llama cuentos del animal-novio, como La bella y la bestia o El rey rana. La mención de los cuentos infantiles no es arbitraria, pues algunas de las comedias sentimentales que comentamos se basan en textos que reconocen esta fuente en sus títulos, como la novela El despertar de la Cenicienta o la comedia Cuento de hadas, de las que hablaremos después. Por otro lado, bajo el conservadurismo del cronotopo de la ingenua, los psicoanalistas, que tanta importancia dan a las psicopatologías derivadas de las relaciones familiares, pueden encontrar un filón de trastornos. Después de todo, hablan de la edad de consentimiento sexual, que actualmente se sitúa entre los 14 y 16 años, y de las tradiciones culturales y las presiones sociales y religiosas que condicionan la libertad sexual de las mujeres.

En efecto, en los cuentos como La Cenicienta o Blancanieves el novio apenas aparece. Lo que narran estos dos cuentos es cómo la protagonista, en la rivalidad que mantiene con sus padres o padrastros, comprende que estos solo quieren que madure para cuando deje la casa y funde su propio hogar. En el cuento del animal-novio, este es coprotagonista y la mujer expresa un miedo al sexo que termina superando. Deja de ver el sexo como un monstruo o un instinto salvaje. En el cine que comentamos, la presencia y protagonismo del novio de la ingenua varía mucho. Están siempre juntos en Yo quiero morir contigo (1941), de la que luego hablaremos. En otros casos, el novio lo está de forma implícita, sobre todo, si consideramos que en algunas películas el novio de la madre es el novio de la hija, como en Dama de compañía, o bien la aceptación de un nuevo padre, como en El tercer beso (1943), o su rechazo, como en Dieciséis años, esconde un deseo sexual oculto. Por otro lado, en el cine de ingenuas, con excepción de El tercer beso, este novio, en lugar de poseer un perfil salvaje, es un hombre refinado, experimentado y mayor. Es decir, si tomamos las Máscaras masculinas de Enrique Gil Calvo, ${ }^{24}$ el animal-novio es la máscara negativa del «monstruo»: el hombre temible, el criminal, el drogadicto, el seductor... En cambio, el novio de las ingenuas podría ser la máscara positiva del monstruo: el genio creador o el genio romántico. Pero, en realidad, las

22 Gómez Tello, José Luis, «Su primer baile», Primer Plano, 16 de junio de 1946, s. p.

23 Bettelheim, 2006 [1975].

24 Gil Calvo, 2006. 
ingenuas se enamoran de artistas bastante convencionales, pues su creación (su música, sus cuadros) no es, en absoluto, destructora. Más bien, la narrativa conservadora, quiere que esos novios sean la máscara del «patriarca»: el hombre responsable, que protege y gobierna. Es como si la ingenua-huérfana se casase o encontrase al padre. Quien se acerca al animal-novio son los personajes de Ángel Magaña. Encarna un joven sensible, casi un poeta, un Werther, un enamorado del amor.

Precisamente en 1947 se presentan, además de Canción de cuna, de la que ya hemos hablado, dos películas de Ángel Magaña que desarrollan esta máscara. La primera, Adolescencia (1942), se había presentado en Barcelona en julio de 1946. En Madrid solo está tres días en cartel, pero Primer Plano dice que es «de las mejores comedias que nos haya ofrecido el cine criollo y hasta iguala a muchas de las producciones americanas». ${ }^{25}$ Aquí Tito (Ángel Magaña) es esa cara positiva del monstruo. En su primera intervención, él ya deja claro que no es de esos que viajan (la máscara del héroe) sino de los que están al lado de su amada (la máscara del romántico). Esa amada se llama Elvira, su vecina y su gran amor desde la infancia. Pero Elvira conoce a Raúl, un hombre de mayor edad, venido de Estados Unidos, que tiene coche y un buen negocio. Hay un momento en que Elvira recibe flores de Tito y de Raúl y su padre le pregunta cuál de los dos le gusta más. Ella dice que le gustan los dos: «Tito es una monada. Tiene gran corazón y se desvive por mí. [...] Tan bueno, tan simpático». Pero Elvira se casa con el segundo pretendiente, el prototipo del amor de la ingenua, porque: «Raúl es tan interesante, nunca había conocido un hombre así, reposado, serio. Al lado de él me siento como amparada». Elige, en definitiva, la máscara del patriarca. ${ }^{26}$

Ángel Magaña también protagoniza Yo quiero morir contigo. El personaje que interpreta, Mauricio, juega a ser un monstruo romántico. Moviliza las pulsiones de Eros y Tánatos. Decimos que juega porque cuando queda con Laurita en un hotel para suicidarse juntos lo que pretende, en realidad, es acostarse con ella. Pero, de pronto, la trama se complica con un asunto policial, un crimen y un viaje para rescatar a un niño secuestrado. Es decir, al final de la película, descubrimos que la ingenua había caído en una trampa de su novio. El suicidio era una excusa para llevarla a un hotel. Pero

25 Gómez Tello, José Luis, «Adolescencia», Primer Plano, 25 de mayo de 1947, s. p.

26 La película también tiene su interés ya que, al adoptar el punto de vista masculino sobre el primer amor, nos muestra la insistencia en asignar roles diferentes a cada sexo. Dice Tito tras perder a Elvira: «El primer amor del hombre jamás se realiza. Los muchachos no nos casamos nunca con la primera novia. Pero a la primera novia jamás se la olvida». 
todo se estropea porque se entromete un niño secuestrado, fantasma del embarazo. Por la cuestión del suicidio, la Iglesia la clasifica para mayores de 21 años. Primer Plano dice que hay un buen trabajo de Ángel Magaña y que la película es distraída y de buena comicidad, con una intriga conducida con habilidad por Mario Soffici, manteniendo el interés del público. ${ }^{27}$

En años posteriores, seguirán estrenándose en Madrid otros títulos. Llegan a la capital muy tarde respecto a su fecha de producción, aunque en algún caso se han estrenado antes en provincias. Por ejemplo, producida por Lumiton y dirigida por Francisco Mugica, El viaje (1942) se estrena en Madrid el 28 de marzo de 1949. El 4 de septiembre de 1949 es el turno de El tercer beso. La película había llegado a España en 1947 y la censura la había autorizado solo para mayores de edad el 23 de septiembre, lo que impedía, una vez más, que llegase al público «ingenuo». Además, había recibido todo tipo de descalificaciones de los censores: «escasísimo valor», «gauchada muy atorrante», «una tontería que le da a uno vértigo», «mala de argumento, mala de realización, mala de interpretación». ${ }^{28}$

\section{La máscara de la pituca: la feminidad de la «moderna»}

Por otra parte, el modelo de mujer que propone el cronotopo de las ingenuas tiene en el cine argentino un contramodelo que plantea otra forma de femineidad en las novias y da cuenta de la pluralidad del cine porteño. Sin embargo, no llegó a la España franquista o llegó con menos impacto y de forma aislada, sin formar una línea sostenida. La razón de esta ausencia se explica en los problemas comerciales que tuvo el cine argentino para entrar en España y en la actitud de la censura española. Un ejemplo paradigmático es el cine de Paulina Singerman, la contrafigura de la ingenua. Sus personajes femeninos, rebeldes y alocados, pero de buen fondo, también buscan el idilio de amor y el casamiento. Pero lo hacen tomando la iniciativa y provocando todo tipo de desórdenes. Nada la detiene con tal de enamorar al hombre del que le separa la clase social, un vínculo doméstico, otra mujer o, simplemente, la pasividad del amado. Esta forma de comportarse hace que sus personajes, algunos de ellos todavía en minoría de edad, entonces en los 21 años, parezcan más adultos. Es decir, la ingenua es una mujer infantilizada que necesita una actriz de unos 16 años. En cambio,

27 Gómez Tello, José Luis, «Yo quiero morir contigo», Primer Plano, 14 de julio de 1946, s. p.

28 El tercer beso, 23 de septiembre de 1947, AGA, c. 36/03301. 
Singerman interpreta sus personajes menores de 21 cuando su edad real supera los 26 años.

La situación inicial que más se repite en el cine de Singerman es la de una mujer a punto de casarse que se vuelve atrás. Ella todavía no ha tenido el primer amor de verdad, pero la edad la presiona y la lanza al casamiento con un cualquiera. La razón por la que la caprichosa va a casarse, pese a no estar enamorada, se explica en Isabelita (1940). Un grupo de mujeres está bebiendo y fumando. Celebran la despedida de boda de Alcira (Paulina Singerman). Esta comenta por qué ha decidido casarse:

-Yo sé lo que queremos decir todas. No hace falta gritar. Que los hombres son unos idiotas, ¿no es eso? Que son unos necios, unos engreídos, que no son capaces de hacer la felicidad de una mujer. Todas lo sabemos. Pero todas nos casamos. Es un descrédito quedar para vestir santos en nuestra sociedad. Por eso, una pena, nos casamos con el primer fantoche con aspecto de hombre que se nos presenta. (Toma una copa de la bandeja de un camarero vestido con smoking.) ¡Ay, si conoceré yo a los hombres! Todos los que he tratado desde chica, excepción de papá, son unos monigotes.

- ¡Alcira, por favor, que aquí hay un hombre!

-Eso no es un hombre. Es un maître.

Naturalmente, al final, la protagonista encuentra el amor y se casa.

Pues bien, de la filmografía de Paulina Singerman, diez títulos entre 1938 y 1944, solo tres llegan a España y con problemas. La primera película, La rubia del camino (1938), se estrena en Madrid en 1940 y la censura la prohíbe un tiempo porque Italia la considera ofensiva por el desprecio y el dominio con el que la protagonista trata a un conde italiano que la pretende. Hay que modificarla para que vuelva a las salas. La rubia del camino es el filme en el que el guionista y director Manuel Romero fija la personalidad de la caprichosa, inspirándose en la screwball comedy y desarrollándola después en otros títulos. Cuando en la película los padres se lamentan de que su hija, Isabel (Paulina Singerman), es insufrible, el abuelo da la clave de la personalidad de la pituca. Dice: «Es lo que todos hemos hecho de ella: una chica moderna». En efecto, el dinero, la fortuna familiar, hace libre a la caprichosa, de modo que los padres esperan que se case con un hombre que la dome, un hombre que, haciéndola sufrir de amor, consiga que deje de ser engreída, mimada, despótica, insolente, rebelde y mal hablada. «iQue se case pronto!», dicen los padres de Isabel para perderla de vista. Y, en efecto, se casa, pero sin perder los dos rasgos que aquella sociedad condena en la mujer: ser caprichosa y ser moderna. El rasgo «caprichosa» alude a que se condena cualquier comportamiento agresivo en la mujer: que diga lo que 
piensa y ofenda, que se burle de los demás, que cree en otros sentimientos de culpa, sus rabietas, su egoísmo, sus palabras inadecuadas, contestar al novio, desobedecer a los padres y, en fin, que no controle sus impulsos y, al mismo tiempo, sea controladora. Moderna alude a un conjunto de hábitos impropios de una señorita: fumar, beber, salir sola con hombres, querer trabajar...

Esta personalidad se repite en Mi amor eres tú, también de Manuel Romero. Aquí Singerman es una jovencita huérfana, Susana, pero una huérfana muy diferente de las ingenuas. Enamorada de su tutor, consigue con todo tipo de artes que deje a su novia y se case con ella. Dice Susana al final del filme: «Ya no eres mi tutor. Pero ahora soy yo quien te tutela a ti, niño grande. $Y$ he de hacerte feliz a pesar tuyo, porque te quiero, porque mi amor eres tú». ${ }^{29}$ La película se importa en noviembre de 1945, es decir, llega a España «confundida» entre el cine de ingenuas. Pero se prohíbe en su pase por censura el 30 de enero de 1946. No obstante, un mes más tarde se autoriza para mayores de 16 años sin que consten en el expediente explicaciones. ${ }^{30}$ Sin duda el personaje femenino debió crear un debate. A Madrid no llega hasta 1947 y la crítica dice que es una película de calidad discreta, aunque reseña que consigue el interés y la sonrisa del público. ${ }^{31}$

Finalmente, en 1948, llega a Madrid Luisito (1943), estrenada en España con el título Una mujer con pantalones. Aquí Singerman se viste de hombre y trabaja como secretario del galán que ama para maquinar y conseguir que se case con ella. Vestir a la pituca de hombre es como demostrar su falta de feminidad. La película se había importado en 1947 en sustitución de la película francesa Les yeux noirs (1935), que había sido prohibida porque parte de la acción giraba en torno a un «restaurante de citas» en la Rusia de 1913. En el caso de Luisito, los censores no ven dificultades morales, pero la trituran: sin valor alguno, intrascendente, demasiado «rosa», inverosímil y a veces un tanto bufa y de vulgar interpretación. En consecuencia, se aprueba sin cortes, pero solo para mayores de 16 años y castigada en sus posibilidades de explotación económica, es decir, de tercera categoría. ${ }^{32} \mathrm{La}$ crítica española, en cambio, dice que es una comedia risueña y grata y alaba las cualidades interpretativas de Paulina Singerman. ${ }^{33}$ Prueba de su éxito es que la distribuidora comienza la explotación con nueve copias y, en junio de 1948, tras el estreno en Madrid, tira tres copias más.

29 La trama recuerda Angela María (1924), de Carlos Arniches y Joaquín Abati.

30 Mi amor eres tú, 30 de enero de 1946, AGA, c. 36/03248.

31 Gómez Tello, José Luis, «Mi amor eres tú», Primer Plano, 15 de junio de 1947, s. p.

32 Una mujer en pantalones, 14 de mayo de 1947, AGA, c. 36/03289.

33 Gómez Tello, José Luis, «Una mujer con pantalones», Madrid, 4 de julio de 1948, s. p. 


\section{TABLA 1}

\section{EL CRONOTOPO DEL PRIMER AMOR}

\begin{tabular}{|c|c|}
\hline El cronotopo de la ingenua angelical & El cronotopo de la pituca moderna \\
\hline $\begin{array}{l}\text { El tema es el primer amor, que es ya el } \\
\text { amor definitivo. }\end{array}$ & $\begin{array}{l}\text { El tema es el primer amor, que se ha dado } \\
\text { por imposible de encontrar. }\end{array}$ \\
\hline $\begin{array}{l}\text { Este tema se expresa de una forma cómi- } \\
\text { ca y sentimental acorde con el carácter de } \\
\text { la ingenua y, por lo tanto, con un humor } \\
\text { tierno, risueño y un amor inocente, casi } \\
\text { contenido. } \\
\text { Siete mujeres. Mirtha Legrand-Carmen: } \\
\text { «Me veo a tu lado durante años y años. En } \\
\text { un lugar siempre el mismo. Siempre bajo } \\
\text { un techo nuestro. Y entonces le doy gracias } \\
\text { a Dios por haberme puesto en el mundo». }\end{array}$ & $\begin{array}{l}\text { Este tema se expresa de una forma cómica } \\
\text { y sentimental acorde con el carácter de la } \\
\text { pituca y, por lo tanto, con un humor sarcás- } \\
\text { tico y un amor dominante, casi agresivo. } \\
\text { Noche de bodas (1942). Singerman-Lucía: } \\
\text { «Al entrar en la casa aquella lo vi a usted } \\
\text { en un ángulo nuevo. Lo vi en marido. Lo } \\
\text { vi ridículo». }\end{array}$ \\
\hline $\begin{array}{l}\text { La fábula se articula sobre la meta del idi- } \\
\text { lio amoroso. Se trata de logar el amor se- } \\
\text { xual sin que el sexo se exprese y sin perder } \\
\text { el amor familiar. } \\
\text { El viaje. Mirtha Legrand-Alicia: «Me gus- } \\
\text { taría casarme y fundar un hogar con mu- } \\
\text { chos hijos. Pero antes de mi felicidad está } \\
\text { la de mi madre. He hecho la promesa de } \\
\text { consagrarme a ella mientras esté enferma». }\end{array}$ & $\begin{array}{l}\text { La fábula se articula sobre la meta del } \\
\text { idilio amoroso. Se trata de logar el amor } \\
\text { sexual seduciendo, sin importar el amor } \\
\text { familiar y sin renunciar a nada. } \\
\text { Elvira Fernández, vendedora de tienda } \\
\text { (1942). Singerman-Elvira: «Ya no soy la } \\
\text { muñeca de antes. Soy una mujer que quie- } \\
\text { re profundizar en todos los aspectos. Que } \\
\text { quiere vivir como un ser humano entre } \\
\text { los seres humanos. Que quiere conocer la } \\
\text { causa, el porqué de todo lo que le sale al } \\
\text { paso». }\end{array}$ \\
\hline $\begin{array}{l}\text { El reparto está lleno de mujeres y los tí- } \\
\text { tulos de crédito los encabezas la actriz } \\
\text { adolescente que interpreta el personaje de } \\
\text { ingenua. }\end{array}$ & $\begin{array}{l}\text { El reparto lo encabeza una mujer, una ac- } \\
\text { triz adulta que interpreta el personaje de la } \\
\text { pituca. }\end{array}$ \\
\hline $\begin{array}{l}\text { El espacio más representativo es un hogar } \\
\text { roto o incompleto. }\end{array}$ & $\begin{array}{l}\text { El espacio es un viaje que supone dejar el } \\
\text { hogar y cambiar de ciudad, de barrio, de } \\
\text { amistades, de clase social... }\end{array}$ \\
\hline $\begin{array}{l}\text { El tiempo corresponde a la adolescencia } \\
\text { y a los primeros grandes hitos del amor: } \\
\text { el primer novio, el primer baile, el primer } \\
\text { beso... } \\
\text { Los martes, orquídeas. Mirtha Legrand-El- } \\
\text { vira: «Muchas veces estoy en una noche } \\
\text { de luna. Admirada de un joven de ojos } \\
\text { soñadores que me toma las manos y me } \\
\text { habla de amor mientras a lo lejos se oyen } \\
\text { cantos». }\end{array}$ & $\begin{array}{l}\text { El tiempo está ligado a la mayoría de edad } \\
\text { y a la presión de casarse. } \\
\text { Mi amor eres tú. Singerman-Susana: «Yo } \\
\text { soy la única que debe casarse sin amor. } \\
\text { La única que debe elegir un hombre apre- } \\
\text { miada por el tiempo. Por el egoísmo de los } \\
\text { demás». }\end{array}$ \\
\hline
\end{tabular}

Fuente: Elaboración propia. 


\section{La versión española}

Por lo que se refiere a la comedia sentimental española sobre el idilio del amor previo al matrimonio, como en el caso del cine argentino, la mayoría reproduce, con adaptaciones literarias nacionales, el modelo estadounidense de comedia rosa, cuya inspiración llega directamente de Hollywood o bien se recibe a través de otro de sus imitadores: el cine italiano de teléfonos blancos. La producción es muy abundante ${ }^{34}$ y con éxito entre el público. Si bien su temática, las relaciones de pareja, hace que el Estado clasifique parte de esta producción como apta solo para mayores de 16 años. La Iglesia española es aún más dura y califica numerosos títulos para mayores de 21 años. Esto resulta exagerado si tenemos en cuenta que estas películas han pasado la censura del guion y, en consecuencia, se les ha advertido de que se cuide la exhibición del cuerpo femenino de las protagonistas, que su vestuario sea pudoroso, que si bailan no lo hagan con movimientos obscenos, que si van a un cabaret o salas de fiestas los números de los artistas sean decorosos, que eviten libertades de trato y relación y que cuando, al final, besen al hombre con el que acaban de casarse o el que será su futuro marido el beso sea breve o casto. ${ }^{35}$

Pues bien, de esta producción, llegan bastantes títulos a Buenos Aires. Allí pasan la censura sin problemas y son clasificadas para todos los públicos, pero merecen, en general, una pobre valoración crítica. ${ }^{36}$ Por otra parte, el público del cine español en la Argentina es un público de emigrantes que prefiere el cine musical-folclórico y un humor más sainetesco. De hecho, la mayoría de los títulos que vamos a citar se estrenan en el cine Gloria, especializado en programas para la emigración española. Al mismo tiempo, el hecho de que Cifesa, una de las productoras que más cine rueda de este tipo, no pueda exportar películas por estar en la lista negra de los aliados por fascista hace que la comedia sentimental española llegue a la Argentina en

34 Castro de Paz, 2002, 85 y ss.

35 Un ejemplo, aunque este título no se intercambió, es Boda accidentada (1942). El dictamen censor dice: «se consuma un acto de adulterio que se pretende dejar paliado en el momento de que la inmoralidad se está produciendo con la muerte del marido del protagonista y con el ulterior casamiento de los adúlteros [...] cae en grandes vulgaridades». En cambio, en ese mismo expediente, un informe que da cuenta de su estreno en Jerez de la Frontera el 21 de junio de 1948 dice, a la vista de la reacción del público, que es una película de una comicidad extraordinaria magníficamente interpretada. Boda accidentada, 26 de mayo de 1941, AGA, c. 36/04550.

36 Bien es cierto que utilizamos en la mayoría de los casos un medio, el Heraldo del Cinematografista, que era duro con el cine español. Intentaremos equilibrar su juicio con el que emite en España Méndez-Leite. 
dos oleadas: antes y después de la firma del acuerdo cinematográfico entre España y la Argentina de septiembre de 1948, momento a partir del cual Cifesa montará una sucursal en Buenos Aires para exportar sus películas directamente.

Por otro lado, en estas películas exportadas es más frecuente la figura de la pituca ${ }^{37}$ que de la ingenua. En España las actrices nacionales que más se aproximan al personaje de la ingenua son Isabel de Pomés y Josita Hernán. La primera es la que más se parece en el físico. Tenía entre 19 y 21 años cuando hace Huella de luz (1943), Noche fantástica (1943), la más parecida al cine de ingenuas argentino, pero que no se ve allí, y Te quiero para mí (1944). ${ }^{38}$ Esta última trata de un profesor tímido (Antonio Casal) que se enamora de una joven alumna (Isabel de Pomés) con la que se termina casando. Se estrena en Buenos Aires el 29 de junio de 1945 y es una de las comedias españolas mejor valorada por el Heraldo del Cinematografista de todas las estrenadas en la Argentina en este primer periodo. El Heraldo dice que es amena, risueña, sentimental y con una atrayente actriz protagonista, aunque resulta lenta y el diálogo poco natural en algunos momentos. ${ }^{39}$

Huella de luz se estrena muy tarde, en 1951. Es la historia de un triste oficinista (Antonio Casal) que es invitado por su jefe a pasar unos días en un lujoso hotel. Allí conoce a una joven rica y amable (Isabel de Pomés) de la que se enamora. Pese a las diferencias de clase se terminan casando. El Heraldo escribe que es un filme corriente por su tema, muy conocido, se desarrolla sin imaginación y parco en gracia y la dirección y los actores son mediocres. Solo puede interesar, dice, a la colonia española. ${ }^{40}$

Josita Hernán, ${ }^{41}$ por su parte, tiene al menos 25 años cuando interpreta su primera película de la postguerra y pronto alternará los personajes de ingenua con los de pituca o hace ambos papeles al mismo tiempo, como en La niña está loca (1943). Es decir, físicamente, Josita Hernán es menos mujer-niña y, psicológicamente, sus personajes de ingenua tienen un punto de travesura y desparpajo que no se da en el modelo argentino. En La tonta del bote (1939), sobre la obra del mismo título escrita en 1925 por Pilar Millán Astray, Josita Hernán es Susana, una joven y alegre huérfana, que trabaja como empleada doméstica en una pensión, donde conoce al amor

37 La pituca española viene a ser la mujer «activa» en palabras de Gil Gascón, 2010, 427.

38 Sin embargo, no construye su carrera sobre este tipo de papeles y parte de la crítica española dice que su ingenuidad es insípida. Rodríguez Fuentes, 2001, 506-508.

39 «Te quiero para mí», Heraldo del Cinematografista, Buenos Aires, 4 de julio de 1945, 93.

40 «Huella de luz», Heraldo del Cinematografista, 28 de noviembre de 1951, 285.

41 Gómez García, 2018, 97 y ss. 
de su vida, un bailarín. Se estrena en Buenos Aires muy tarde, el 26 de octubre de 1950. Heraldo del Cinematografista dice que es «de primitiva realización e interpretación», aunque con detalles sonrientes, gracejo diálogo y una Josita Hernán simpática en algunas partes. Tendrá, dice, discreta acogida entre el público español. ${ }^{42}$ De hecho, para hacerla más atractiva a este público, en la Argentina La tonta del bote se titula El bailarín español. Pero, como decíamos, Josita Hernán también hace numerosos personajes de pituca y con sus papeles en La niña está loca, Ella, él y sus millones (1944), Ángela es así (1945) o Un hombre de negocios (1945) viene a ser la Paulina Singerman española.

Por lo que se refiere a la primera ola exportadora, España envía tres películas basadas en las novelas rosas de Luisa-María Linares, inspiradas, a su vez, en las comedias de Hollywood. Linares fue una escritora muy leída por el público femenino y con numerosas adaptaciones al cine entre 1940 y $1945 .{ }^{43}$ De las estrenadas en Buenos Aires, la mejor valorada por el Heraldo del Cinematografista es Te quiero para mí, de la que ya hemos hablado. El 13 de septiembre de 1945, formando ambas un programa doble en el cine Gloria, se estrenan Un marido a precio fijo (1942) y Doce lunas de miel (1944). Un marido a precio fijo contiene una clara figura de la pituca. Méndez-Leite en España dice que es un filme simpático y estimable donde brilla la interpretación de los dos protagonistas. ${ }^{44}$ Heraldo escribe que es un asunto trillado y previsible, pero con buena interpretación, tono risueño, diálogo gracioso, ritmo movido y elegantes interiores y exteriores de Mallorca. ${ }^{45}$ En realidad, a diferencia de las películas de Paulina Singerman, aquí la pituca es domesticada por su marido alquilado, que la encierra en un refugio en la montaña y la obliga a llevar las labores de la casa. En cuanto a Doce lunas de miel, Méndez-Leite dice que es uno de los mejores trabajos de Vajda y que tiene una fina comicidad. ${ }^{46}$ Heraldo del Cinematografista escribe que el asunto es bueno y la comicidad está lograda en algunos episodios, pero es lenta y la labor de los intérpretes, discreta. ${ }^{47}$ También en 1945 se estrena La boda de Quinita Flores (1943), sobre una obra de los Álvarez Quintero. En España, Méndez-Leite la considera una comedia de fino matiz, dirigida

42 «La tonta del bote», Heraldo del Cinematografista, 19 de noviembre 1950, 260.

43 Fragero Guerra, 2004, 223 y ss.

44 Méndez-Leite, 1965, I: 427-428.

45 «Un marido a precio fijo», Heraldo del Cinematografista, 19 de septiembre de 1945, 80.

46 Méndez-Leite, 1965, I: 460.

47 «Doce lunas de miel», Heraldo del Cinematografista, 19 de septiembre de 1945, 87. 
con maestría y ajustada interpretación. ${ }^{48}$ Heraldo del Cinematografista dice que es muy lenta, teatral y de interpretación poco acertada. Es un filme de complemento, para acompañar a otro de mayor importancia. ${ }^{49}$

Durante el año 1946, se presentan en Buenos Aires otras tres comedias sobre el cronotopo del primer amor. El novio de Carmencita es el título argentino de la película hispano-fascista Lluvia de millones/Fortuna (1940). El Heraldo dice que las situaciones dramáticas se repiten y cansan, pero hace reír, hay varias canciones presentadas con buen gusto y la interpretación es correcta. ${ }^{50}$ Turbante blanco (1945), por su parte, es una comedia rosa de equívocos entre dos parejas dirigida por Ignacio F. Iquino. No gusta al crítico del Heraldo. Dice que es una comedia «inorgánica» que sin éxito ha pretendido seguir las farsas disparatadas del cine norteamericano. Pero añade que puede hacer reír a los públicos poco exigentes ${ }^{51}$ Idilio en $\mathrm{Ma}$ llorca (1942) cuenta otra historia de novia en fuga, aquí llamada Magdalena (Antoñita Colomé). El Heraldo dice que tiene un asunto trillado, la acción lenta y es una producción vieja, pero está muy bien la protagonista y el fondo musical es bueno. Considera que es una película para públicos de nacionalidad española. ${ }^{52}$

Finalmente, el 20 de enero de 1948 se estrena Ángela es así. En España se había elogiado la gracia femenina de su protagonista, Josita Hernán, y la cuidada adaptación de la comedia Ángela María (1924) de Carlos Arniches y Joaquín Abati. ${ }^{53}$ El Heraldo dice que «la audacia de una bella colegiala provoca la constante carcajada del espectador», aunque la considera una película de complemento. ${ }^{54}$

Cómo decíamos, a partir de 1950, con La tonta del bote, se inicia un nuevo ciclo de exportación a la Argentina de comedias sentimentales. Pero la recepción crítica tampoco es buena. Llegan muy tarde respecto a su fecha de producción y se basan en un modelo ya gastado por docenas de películas bajo similares premisas. Sobre todo, llegan producciones de Cifesa, que reanuda la exportación bajo el sello Cinematográfica Hispánica y decide mandar cinco comedias sentimentales que, aunque en su mayoría viejas, considera que pueden tener buena acogida. Las dos primeras, estrenadas en

48 Méndez-Leite, 1965, I: 447

49 «La boda de Quinita Flores», Heraldo del Cinematografista, 17 de octubre de 1945, 69-70.

50 «El novio de Carmencita», Heraldo del Cinematografista, 6 de marzo de 1946, 31.

51 «Turbante blanco», Heraldo del Cinematografista, 13 de noviembre de 1946, 196.

52 «Idilio en Mallorca», Heraldo del Cinematografista, 9 de octubre de 1946, 170.

53 Méndez-Leite, 1965, I: 484-485.

54 «Ángela es asì», Heraldo del Cinematografista, 22 de octubre de 1948, 17. 
1951, son Huella de luz, de la que ya hemos hablado, y Ella, él y sus millones, titulada en la Argentina Mi mujer es un negocio. Como el matrimonio no se consuma hasta el final, podemos decir que es un filme sobre el primer amor. La película se basa en la comedia teatral de Honorio Maura Cuento de hadas. Heraldo dice que solo se salva la interpretación de Josita Hernán. ${ }^{55}$

En 1951 también se estrena Si te hubieras casado conmigo (1948), un título de producción más reciente que recuerda a La vida en un hilo, que abordaremos después. Victoria (Amparo Rivelles) está casada con Carlos (Adriano Rimoldi), pero este va tras otras mujeres y no se ocupa de ella. Pero, en realidad, lo que estamos viendo es el argumento de una novela titulada Si te hubieras casado conmigo que ha escrito Enrique (Fernando Rey) para mostrarle a Victoria cómo sería su vida si en lugar de casarse con él, lo hiciera con Carlos. El resto de la película es la disputa de Carlos y Enrique por ganarse el amor de Victoria. Ella, finalmente, elije al escritor. Gil Calvo diría que Victoria se enamora de la máscara masculina del monstruo, pero ella lo disecciona en dos personalidades con el deseo de librarse de la cara oscura (Carlos) y quedarse con la cara romántica (Enrique). Heraldo del Cinematografista dice que es una película de categoría especial y escribe: «Hay amable entretenimiento y rasgos originales en esta comedia española, ciertamente destinada a hacer buen negocio en su colectividad y a servir de buen refuerzo a cualquier otro programa». ${ }^{56} \mathrm{Es}$, por lo tanto, la comedia española sentimental mejor acogida en este segundo periodo.

En 1952, se estrenan cuatro títulos. Tres de ellos llegan con diez años de retraso. Son: Eloísa está debajo de un almendro (1943), de Cifesa, La niña está loca, titulada en la Argentina La bailarina de Sevilla, y Cristina Guzmán, profesora de idiomas (1943). Curiosamente, las tres tienen en común que plantean un desdoblamiento, es decir, un personaje femenino representa las dos caras de toda máscara. Eloísa está debajo de un almendro es una comedia sentimental con el mundo peculiar de Jardiel Poncela, incluidas sus alusiones al cine. Aquí Mariana (Amparo Rivelles) es la viva imagen de Eloísa, una mujer asesinada hace años. En España MéndezLeite habla de una adaptación lograda ${ }^{57}$ mientras el Heraldo escribe que la película ha perdido los elementos cómicos de la obra de Jardiel Poncela, incluido su sabroso y chispeante diálogo, y se ha quedado en un folletín

\footnotetext{
55 «Mi mujer es un negocio», Heraldo del Cinematografista, 19 de diciembre de 1951, 299. $1951,228$.

56 «Si te hubieras casado conmigo», Heraldo del Cinematografista, 19 de septiembre de

57 Méndez-Leite, 1965, I: 454-455.
} 
de intriga. ${ }^{58}$ La niña está loca, por su parte, es la historia de una aspirante a artista (Josita Hernán) que, tras un accidente de tren, es confundida con una millonaria (Josita Hernán), enredo del que sale encontrando el hombre de su vida (Ismael Merlo). El doble papel le permite a la actriz hacer de la pituca malvada (mujer frívola, nerviosa, impertinente y antipática) y el de la bondadosa. Heraldo dice que el título La bailarina de Sevilla no se justifica y que la sustitución de personalidades está muy gastada. Se trata de una película, concluye, que solo tiene posibilidades con la colectividad española. En cuanto a Cristina Guzmán, se basa en la novela del mismo título de Carmen de Icaza, destacada dirigente de Falange. Aunque los estudiosos se han dividido sobre la ideología que representa la personalidad de la protagonista del relato, ${ }^{59}$ la película responde a los moldes patriarcales y conservadores. Una mujer viuda (Marta Santaolalla) se hace pasar por la mujer alocada (pituca) de un millonario (Ismael Merlo) con el fin de que este se cure del trauma que le generó el abandono de su mujer. En su momento, en España fue considerada una película amena, de buen ritmo y excelente interpretación. ${ }^{60}$ El Heraldo del Cinematografista dice que es «un anticuado folletín de recursos infantiles y desarrollo apagado [...] interpretación falsa y la dirección pesada». ${ }^{61}$

En 1953, se estrenan La doncella de la Duquesa (1941) y Un hombre de negocios, titulada en Argentina Mi tío de la Habana. Esta vez, ambas tienen en común una cierta referencia a América. Heraldo dice de la primera: «Su primitiva técnica y la simpleza de los recursos la hacen apta solamente como complemento en programas para la colectividad española». ${ }^{62}$ De Un hombre de negocios, el Heraldo escribe que está hecha con medios modestos y llega tarde. Insiste en que «la historia ya fue usada muchas veces en el cine». ${ }^{63}$

\section{Fortuna o voluntad}

Hemos dejado para el final dos películas estrenadas el mismo año, pero presentadas en la Argentina con tres años de diferencia: El destino

58 «Eloísa está debajo de un almendro», Heraldo del Cinematografista, 5 de noviembre de $1952,145$.

59 Fragero Guerra, 2004, 134.

60 Méndez-Leite, 1965, I: 445.

61 «Cristina Guzmán», Heraldo del Cinematografista, 5 de noviembre de 1952, 146.

62 «La doncella de la Duquesa», Heraldo del Cinematografista, 15 de agosto de 1953, 102.

63 «Un hombre de negocios», Heraldo del Cinematografista, 10 de octubre de 1953, 164. 
se disculpa (1945), de José Luis Sáenz de Heredia, estrenada muy pronto en Buenos Aires, el 1 de noviembre de 1945, y La vida en un hilo (1945), de Edgar Neville, presentada en agosto de 1948. Son de las comedias más interesantes porque ensanchan el modelo que hemos descrito y tienen una visión del mundo opuesta que abre un debate sobre el contenido del cine franquista. Además, ambas abordan el idilio amoroso (si bien en la primera es una subtrama) en clave de comedia fantástica, pero de baja fantasía para mantener el realismo propio del cronotopo idílico. El modelo son Death Takes a Holiday (1934) o Me casé con una bruja (I Married a Witch, 1942).

La vida en un hilo cuenta la historia de Mercedes (Conchita Montes), una mujer moderna que no soporta la vida provinciana y que acaba de enviudar. Está, por lo tanto, abierta al amor. Mercedes conoce en un viaje de tren a Madrid a una artista de circo que es adivina (Julia Lajos). Pero no predice el futuro, sino que sabe lo que pudo ocurrir y no ha ocurrido. Entonces, Mercedes va contando la vida que vivió con su aburrido, bueno, trabajador y convencional marido, Ramón (Guillermo Marín), y la adivina cuenta «la vida que estuvo a punto de vivir» con el divertido, arbitrario, sin fortuna y artista, Miguel Ángel (Rafael Durán). El primero es la máscara del patriarca y el segundo, del monstruo. Pero un golpe del destino hace que ella se encuentre de nuevo, sin reconocerlo, con Miguel Ángel, el hombre creado para que ella sea dichosa, y, esta vez, la fortuna les junta. Neville señala que con la película muestra «la influencia decisiva que la casualidad tiene en nuestras vidas, el cómo cambia el curso de estas el hecho fortuito». ${ }^{64} \mathrm{La}$ vida en un hilo apenas merece comentario del Heraldo. Se limita a señalar que es una película de complemento y, en efecto, se presenta así en el cine Gloria. Es más, se estrena con el título Romance en España para atraer, al menos, al público español. Méndez-Leite, en cambio, dice que en Madrid fue una grata sorpresa para crítica y público, al que le gustó extraordinariamente, por su calidad excepcional y ser cine cien por cien. ${ }^{65}$

El destino se disculpa, por su parte, plantea una tesis totalmente contraria a La vida en un hilo y a la mayoría de las comedias rosas que hemos comentado con sus golpes de suerte en forma de herencias, premios de lotería y demás golpes de la fortuna. La película se basa en el relato $E l$ fantasma de Wenceslao Fernández Flórez, argumento que tenía origen en un fallido guion encargado por un productor norteamericano. Tiempo después Sáenz Heredia lee el relato y decide llevarlo al cine. Pero introduce un

64 Neville, 1969, 291.

65 Méndez-Leite, 1965, I: 483-484. 
importante cambio. Crea el personaje del Destino. ${ }^{66}$ Este se defiende argumentando que él no dirige la vida de los hombres. No hay ni destino ni azar ni casualidad, pues existe el libre albedrío. Es decir, intervienen en la trama dos personajes fantásticos: uno creado por Fernández Flórez (el fantasma, el amigo muerto del protagonista) y otro por Sáenz de Heredia (el destino, interpretado por un anciano). Sáenz Heredia quería hacer una película a lo Lubitsch. Este había rodado El diablo dijo no (Heaven Can Wait, 1943). Para el Heraldo, El destino se disculpa es, junto a Te quiero para mí, la comedia española de mayor calidad de las estrenadas en la Argentina en esos años. Asegura que tiene momentos divertidos y una idea atrayente. Pero también considera que es fría, lánguida y discretamente interpretada. ${ }^{67}$ Imparcial Film está muy a favor. Escribe que es interesante y original, tiene una técnica equiparable a las producciones americanas y demuestra «el resurgimiento del cine español». ${ }^{68}$

La película es importante también porque es la única de las comedias estrenadas en Buenos Aires que había sido declarada de interés nacional. Es como decir «perfecta para propagar los principios franquistas», los cuales, en consecuencia, estarían en desacuerdo con La vida en un hilo.$^{69}$ En concreto, al introducir el personaje del Destino, Sáenz Heredia expresa la idea fascista de «voluntad». La película comienza con un anciano que nos habla a cámara. Es el Destino. Va a demostrarnos que él no es el culpable de lo malo que nos pasa. El problema es que el hombre aplica mal el libre albedrío. Para convencernos nos cuenta la historia de dos amigos, Ramiro (Rafael Durán) y Teófilo (Fernán Gómez). Estos dejan la ciudad de Soria y se trasladan a Madrid para convertirse en poeta y actor, respectivamente. Les espera «un destino luminoso». Pero todo les va mal. Ramiro lo achaca a la mala suerte y a la fatalidad. Hasta hace un pacto con Teófilo según el cual, si uno muere, el otro volverá del mundo de los muertos para guiarle mejor en sus decisiones. En efecto, Teófilo muere atropellado por un coche, pero Ramiro no le hace caso en sus consejos y lo pierde todo: una herencia que recibió y el amor de la mujer (una pituca) con la que se iba a casar. Ramiro aprende entonces la lección y, en lugar de creer en su mala fortuna y suicidarse, se pone a trabajar y se declara a la chica, una ingenua, que

66 Quesada, 1986, 247.

67 «El destino se disculpa», Heraldo del Cinematografista, 7 de noviembre de 1945, 165.

68 «El destino se disculpa», Imparcial Film, Buenos Aires, 20 de noviembre de 1945, 9.

69 Esta personificación de los principios del Movimiento no le resta calidad a El destino se disculpa, pues la distinción vaticina su repercusión posterior en el cine español. 
siempre le ha querido y que él ha ignorado. El Destino, en definitiva, nos ha dado una lección: en lugar de creer en la suerte, debemos ejercer el libre albedrío actuando guiados por «la moral cristiana y el sentido común».

Podemos decir que, con El destino se disculpa, Sáenz Heredia emplea el género de la comedia sentimental y sus actores más característicos para ir contra su mensaje. Porque no es suficiente, como parece que le basta al régimen, con que, al final, la pituca vuelva al patriarcado. Dice una frase publicitaria de Un marido a precio fijo: «Compró un esposo de emergencia, pero cuando quiso manejarlo se dio cuenta que sería ella la que debería someterse a las exigencias del marido ocasional». ${ }^{70}$ Lo malo para Sáenz Heredia es el modelo social de la alta burguesía que este cine retrata y el hombre ocioso, pasivo y sin voluntad que proyectar. No puede ser que la suerte de los personajes dependa de una herencia, la lotería, una dote o de algo que, en definitiva, no está en sus manos. Incluso Sáenz Heredia se «queja» de esos personajes honrados, pero desesperados y fatalistas típicos de los relatos de Fernández Flórez. Prueba de la falta de voluntad de los personajes de la comedia sentimental es que se repite una y otra vez, sobre todo al comienzo del filme, el motivo de la boda cancelada: la novia se fuga, el novio la planta en vísperas de la ceremonia $-\mathrm{y}$ hasta en el propio día de la boda - o bien la pareja no formaliza los convenios familiares. Así se muestra el miedo, la indolencia o el fastidio con que actúan los personajes ante la presión por casarse. El título Si te hubieras casado conmigo muestra ese desasosiego de escoger el hombre equivocado. De hecho, los personajes cancelan la boda, pero, al mismo tiempo, tienen que buscar en días otra pareja, pues necesitan estar casados para heredar una fortuna, para mantener la respetabilidad, para que el padre pueda decir que ha acabado con el niño o la niña mimada, para formar ese pilar de la sociedad franquista que es la familia. Se comienza con la boda cancelada o con una urgencia por casarse y se acaba con su consagración mediante un beso, un abrazo o, de nuevo, la propia ceremonia de matrimonio.

«Voluntad» es, precisamente, el término que define la decisión de hacer algo (por ejemplo, casarse) por libre albedrío, incluso sin que uno sea motivado a ello (nace de dentro) y a pesar de lo que piensen los demás, pues la voluntad repudia la debilidad y la sumisión. El libre albedrío es la voluntad libre de cada persona para elegir qué quiere ser. La voluntad supera a la razón en el sentido de que conlleva una acción apasionada. En El destino

70 «Un marido a precio fijo», Heraldo del Cinematografista, 19 de septiembre de 1945, 80. 
se disculpa, Ramiro, el aspirante a poeta, no se suicida por su «voluntad de vivir» y sabe que su desgracia la superará con «voluntad de perfección», lo que implica, precisamente, dejar de jugar a ser escritor. Ramiro, en definitiva, sufre una expiación, cambia de identidad y deja de ser un fatalista, en el sentido de persona que cree que, para mal, pero también para bien, los acontecimientos están determinados. Gil Calvo diría que el fatalista es otra manifestación del monstruo, pues muestra el nonsense de la vida.

La idea de voluntad fue, además, muy importante en todos los fascismos. Los falangistas hablaban entonces de «voluntad de Imperio», «voluntad popular», «voluntad de perfección», «voluntad divina», tenían periódicos con el título Voluntad y les gustaba el filme El triunfo de la voluntad (Triumph des Willens, 1935). Es más, para los falangistas, una nación es un pueblo que comparte una voluntad y una fe común. Igualmente, el régimen sabe que el aislamiento internacional lo superará con su «voluntad de poder», expresión que no solo debe interpretarse como su propósito de mantenerse en el poder, de resistir, sino también en su sentido filosófico. Es decir, el fascismo se apropia del concepto «voluntad de poder» de Nietzsche. ${ }^{71}$ La voluntad, dice el filósofo, es el motor fundamental del hombre. Es una energía vital y creativa, un poder, que le permite lograr sus deseos y ocupar el lugar que le corresponde en el mundo. La manada, en cambio, vive satisfecha en la mediocridad y consagra su vida la religión de la comodidad. El nazismo convierte esta voluntad de poder hacer lo que se desea o libre albedrío en voluntad de poder político y hasta darwinismo racial, esto es, en conquista del Estado y superioridad aria.

\section{Conclusiones}

En fin, quienes en España y la Argentina defendían las relaciones cinematográficas como un instrumento de construcción de la Hispanidad propugnaban intercambiar un cine de grandes mensajes políticos, de relevantes hechos históricos, de especial valor documental o informativo. Las comedias blancas eran material de relleno. De hecho, la comedia sentimental española de los años cuarenta ha sido considerada dentro del cine franquista como un género evasivo que permite al público olvidar la dura vida de la postguerra. También podríamos decir que estas películas alivian la

71 Nietzsche, 1972 [1886], 39-40. La obra publicada póstumamente por su hermana fue en parte tergiversada. 
añoranza de España de los emigrantes en la Argentina. En realidad, ya solo por estas dos cosas están cargadas de intención política.

Pero es que, además, si la mayoría de las comedias sentimentales sobre el cronotopo del primer amor rodadas en España se exhiben en la Argentina sin restricciones mientras que, como hemos visto, en España este tipo de filmes se prohíben, sufren cortes o tienen una clasificación moral para mayores de 21 años por parte de la Iglesia, es porque la figura de la pituca y de su familia (ociosa, frívola, liberal, moderna) se consideran perniciosas. Es más, las comedias argentinas y españolas se presentan tarde en cada país por los desacuerdos comerciales derivados del empeño del franquismo en filtrarlas mediante la censura, la clasificación moral o los cupos comerciales. El franquismo solo quiere importar y exportar aquello que socialice a los ciudadanos en los estereotipos de masculinidad y femineidad del Movimiento. Pretende marcar unos roles conservadores en la mujer (mejor ingenua que pituca) y en el hombre (mejor patriarca que monstruo).

Además, considera que es de «Interés Nacional» defender la voluntad y condenar la fortuna (en su doble sentido de riqueza fácil y abandono al destino). La pregunta es: ¿La vida en un hilo defiende la fortuna porque se cuenta desde el punto de vista de una mujer mientras El destino se disculpa aboga por la voluntad porque el protagonista es un hombre? El concepto de feminidad implícito en todas estas películas, como conjunto de características físicas, psíquicas y morales propias de la mujer y en oposición a lo masculino, permite hacer la pregunta, aunque este concepto es en sí mismo fruto de las discriminaciones de género presentes en aquel momento histórico. La respuesta, en concreto, se encuentra en la última película que vamos a citar, Dos cuentos para dos (1947), basada en la novela El despertar de Cenicienta de José Mallorquí Figuerola. Por partida doble los títulos remiten a los cuentos de hadas. En España la película consigue «la franca carcajada del auditorio» y la crítica dice que es una magnífica comedia. ${ }^{72}$ En Buenos Aires se estrena en dos salas en junio de 1952, es decir, con un decalaje de cinco años. Heraldo dice que es una película corriente, de trama pueril e interpretación discreta, pero despierta simpatías y risas en el público predispuesto. ${ }^{73}$

Pero vayamos a la respuesta. En esta comedia sentimental quien cree en la voluntad es Berta (Carlota Bilbao), una manicura con tanto estilo que puede pasar por una pituca. Su novio, Jorge (Tony Leblanc), es un buenazo

72 Méndez-Leite, 1965, I: 417.

73 «Dos cuentos para dos», Heraldo del Cinematografista, 18 de junio de 1952, 74. 
a la espera de un golpe de suerte. Es un fatalista. Recuerda a los personajes de Antonio Casal. Berta le dice a Jorge cuando ella consigue un empleo con mucho mejor sueldo: «No es suerte. Es voluntad. Es, simplemente, que tengo fe, que creo en mí. [...] Dios quiera que algún día cambies de forma de ser. ¡Que feliz seré entonces!» En efecto, como Jorge no acepta vivir de ella y él gana poco o lo ahorrado enseguida se lo da a alguien, solo se podrán casar si Jorge cambia. Era muy común en la época que las bodas se retrasasen por problemas económicos. Por otro lado, si estaba mal visto que una mujer trabajase, era porque revelaba la falta de voluntad del hombre para impedirlo. Pues bien, poco después ella le dice a Jorge: «Lucha, pelea, decídete. Ten conciencia de tu propia estimación. No me ves a mí que soy una mujer. Yo quisiera infundirte esta voluntad mía. Esta energía, esta fe. [...] Me has dicho que nos casaremos cuando tengas dinero. ¿Cuándo lo tendrás?» En efecto, Jorge cambia, pero también le ayuda un golpe de suerte: hereda una «fortuna» y pone su «voluntad» en ofrecerle a su novia una vida de cuento de hadas. Para ello maquina un enredo en el que entra en juego una doble de Berta, interpretada también por Carlota Bilbao. « $\mathrm{Si}$ esto es un sueño, no quiero despertar», dice Berta cuando ve que Jorge ha cambiado y, por lo tanto, ella podrá casarse, dejar de trabajar y vivir en la jaula de oro que Jorge le ha comprado.

En definitiva, el franquismo importa y exporta un cine que propone dos modelos de género a imitar (la ingenua y el patriarca) y dos a evitar (la pituca y el monstruo fatalista). En la pituca, su fuerte voluntad se tergiversa para que parezca capricho. En el monstruo fatalista, la mala fortuna del bajo origen social se tergiversa para que parezca falta de voluntad.

Recibido, 25 de junio de 2020 Segunda versión, 22 de diciembre de 2020

Aceptado, 22 de enero de 2021

\section{Referencias bibliográficas}

Bajtin, Mijaíl, Teoría y estética de la novela, Madrid, Taurus, 1989 [1. ${ }^{\text {a }}$ ed. 1975]. Bettelheim, Bruno, Psicoanálisis de los cuentos de hadas, Barcelona, Ares-Mares, 2006 [1. ${ }^{\text {a }}$ ed. 1975].

Castro de Paz, José Luis, Un cinema herido, Barcelona, Paidós, 2002.

Cobo Romero, Francisco y Ortega López, Teresa María, «Franquismo y represión femenina: reforzamiento del discurso antifeminista y aniquilamiento de la 
experiencia liberadora, 1936-1951», en Anderson, Peter y del Arco Blanco, Miguel Ángel (eds.), Liando con el pasado: represión y memoria de la Guerra Civil y el Franquismo, Granada, Comares, 2014, 65-82.

Delgado Gómez-Escalonilla, Lorenzo, Diplomacia franquista y política cultural hacia Iberoamérica, 1939-1953, Madrid, CSIC, 1988.

Di Núbila, Domingo, Historia del cine argentino, Buenos Aires, Cruz de Malta, 1959.

Diez Puertas, Emeterio, El montaje del franquismo: la política cinematográfica de las fuerzas sublevadas, Barcelona, Laertes, 2002

Echart Orus, Pablo, La comedia romántica del Hollywood de los años 30 y 40, Madrid, Cátedra, 2005.

España, Claudio y Rosado, Miguel Ángel, Medio siglo de cine, Buenos Aires, Editorial Abril/Editorial del Heraldo, 1984.

Figallo, Beatriz J., El protocolo Perón Franco: las relaciones hispano argentinas 1942-1952, Buenos Aires, Corregidor, 1992.

Folguera Crespo, Pilar, «El franquismo. El retorno a la esfera privada (19391975)», en Garrido González, Elisa (ed.), Historia de las mujeres en España, Madrid, Síntesis, 1997, 527-548.

Fragero Guerra, Carmen, «Soñar la vida. La narrativa de Carmen de Icaza (19361960)», tesis doctoral dirigida por el Dr. Rafael Bonilla Cerezo, Universidad de Córdoba, España, 2004. Disponible en: https://helvia.uco.es/xmlui/bits tream/handle/10396/12204/2014000000990.pdf?sequence $=1 \&$ is Allowed $=y$ [Consultado: 04/02/2020].

Gil Calvo, Enrique, Máscaras masculinas. Héroes, patriarcas y monstruos, Barcelona, Anagrama, 2006.

Gil Gascón, Fátima, «Construyendo a la mujer ideal: mujer y censura cinematográfica durante el franquismo (1939-1963)», tesis doctoral dirigida por el Dr. Julio Montero, Universidad Complutense de Madrid, 2010. Disponible en: https://eprints.ucm.es/10214/1/T31303.pdf [Consultado: 14/02/2020].

Gómez García, Alba, «Trayectoria artística de Josita Hernán: actriz, directora y profesora de teatro español (1914-1999)», tesis doctoral dirigida por la Dra. Guadalupe Soria, Universidad Carlos III, Madrid, 2018. Disponible en: http://hdl.handle.net/10016/26820 [Consultado: 14/02/2020].

González Calleja, Eduardo y Limón Nevado, Fredes, La Hispanidad como instrumento de combate, Madrid, CSIC, 1988.

González de Oleaga, Marisa, El doble juego de la hispanidad: España y la Argentina, durante la Segunda Guerra Mundial, Madrid, UNED, 2001.

Jung, Carl Gustav, Tipos psicológicos, traducción de Rafael Fernández de Mauri,

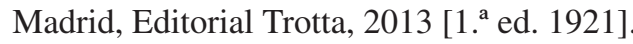

Kelly Hopfenblatt, Alejandro, Modernidad y teléfonos blancos. La comedia burguesa en el cine argentino de los años 40, Buenos Aires, Ciccus, 2019.

Kriger, Clara, Cine y peronismo, Buenos Aires, Siglo XXI, 2009. 
Méndez-Leite, Fernando, Historia del cine español, Madrid, Rialp, 1965, 2 vols.

Neville, Edgar, La vida en un hilo, Madrid, Biblioteca Nueva, 1969.

Nietzsche, Friedrich, Más allá del bien y del mal, introducción, traducción y notas de Andrés Sánchez Pascual, Madrid, Alianza, 1972 [1. ${ }^{a}$ ed. 1886].

Nye, Joseph S., Soft Power, Nueva York, Public Affairs, 2004.

Ortuño Martínez, Bárbara, El exilio y la emigración española de posguerra en Buenos Aires, 1936-1956, Alicante, Universidad de Alicante, 2010.

Quesada, Luis, La novela española y el cine, Madrid, Ediciones JC, 1986.

Richmond, Kathleen, Las mujeres en el fascismo español. La Sección Femenina de la Falange, 1934-1959, Madrid, Alianza, 2004.

Rodríguez Fuentes, Carmen, «Las actrices en el cine español de los cuarenta», tesis doctoral dirigida por el Dr. Emilio C. García Fernández, Universidad Complutense de Madrid, 2001. Disponible en: https://eprints.ucm.es/4517/ [Consultado: 12/02/2020].

Saura, Norma, «Los españoles en el cine argentino: entre el exilio republicano y el nacionalismo hispanófilo: 1936-1956», tesis doctoral dirigida por el Dr. Eduardo Romano, Universidad de Barcelona, 2013. Disponible en: http:// repositorio.filo.uba.ar/handle/filodigital/1514 [Consultado: 14/02/2020].

\section{Filmografía}

Amadori, Luis César, Soñar no cuesta nada, Argentina, Argentina Sono Film, 1941.

Amadori, Luis César, El tercer beso, Argentina, Argentina Sono Film, 1943.

Amadori, Luis César, Luisito [Una mujer en pantalones], Argentina, Argentina Sono Film, 1943.

Arancibia, Ernesto, Su primer baile, Argentina, EFA, 1942.

Capra, Frank, It Happened One Night [Sucedió una noche], Estados Unidos, Columbia, 1934.

Christensen, Carlos Hugo, Noche de bodas, Argentina, Lumiton, 1942.

Christensen, Carlos Hugo, Dieciséis años, Argentina, Lumiton, 1943.

Claire, René, I Married a Witch [Me casé con una bruja], Estados Unidos, Paramount, 1942.

Delgrás, Gonzalo, La tonta del bote [El bailarín español], España, Procines, 1939.

Delgrás, Gonzalo, La doncella de la Duquesa, España, E. C. Cumbre, 1941.

Delgrás, Gonzalo,Un marido a precio fijo, España, Cifesa/Hispania Artis/UPCE, 1942.

Delgrás, Gonzalo, La boda de Quinita Flores, España, Cifesa/Hispania Artis, 1943.

Delgrás, Gonzalo, Cristina Guzmán, profesora de idiomas, España, Cifesa, 1943.

Gil, Rafael, Eloísa está debajo de un almendro, España, Cifesa, 1943. 
Gil, Rafael, Huella de luz, España, Cifesa, 1943.

Iquino, Ignacio F., Turbante blanco, España, Emisora Films, 1945.

Iquino, Ignacio F., Boda accidentada, España, Cifesa, 1942.

Leisen, Mitchell, Death Takes a Holiday, Estados Unidos, Paramount, 1934.

Lubitsch, Ernst, Heaven Can Wait [El diablo dijo no], Estados Unidos, $20^{\text {th }}$ Century Fox, 1943.

Lucía, Luis, Un hombre de negocios [Mi tío de La Habana], España, Cifesa, 1945.

Marquina, Luis, Noche fantástica, España, Cifesa, 1943.

Martínez Sierra, Gregorio, Canción de cuna, Argentina, Producciones Gallart, 1941.

Mugica, Francisco, Los martes, orquídeas, Argentina, Lumiton, 1941.

Mugica, Francisco, Adolescencia, Argentina, Lumiton, 1942.

Mugica, Francisco, El viaje, Argentina, Lumiton, 1942.

Neufeld, Max, Lluvia de millones/Fortuna [El novio de Carmencita], España/Italia, Producciones Hispánicas/Stella, 1940.

Neufeld, Max, Idilio en Mallorca, España, SAFE, 1942.

Neville, Edgar, La vida en un hilo [Romance en España], España, Edgar Neville, 1945.

Orduña, Juan, Ella, él y sus millones [Mi mujer es un negocio], España, Cifesa, 1944.

Perojo, Benito, Siete mujeres, Argentina, Pampa Film, 1944.

Quadreny, Ramón, Ángela es así, España, Aureliano Campa, 1945.

Romero, Manuel, La rubia del camino, Argentina, Lumiton, 1938.

Romero, Manuel, Isabelita, Argentina, Lumiton, 1940.

Romero, Manuel, Mi amor eres tú, Argentina, Lumiton, 1941.

Romero, Manuel, Elvira Fernández, vendedora de tienda, Argentina, ADAP, 1942.

Sáenz de Heredia, José Luis, El destino se disculpa, España, Ballesteros, 1945.

Soffici, Mario, Yo quiero morir contigo, Argentina, Pampa Films, 1941.

Tourjansky, Víctor, Si te hubieras casado conmigo, España, Campa y Suevia, 1948.

Ulloa, Alejandro, La niña está loca [La bailarina de Sevilla], España, Falco, 1943.

Vajda, Ladislao, Doce lunas de miel, España/Portugal, Flaquer/Proartis, 1944.

Vajda, Ladislao, Te quiero para mí, España, Universal Films Española, 1944.

Zabalía, Alberto de, Dama de compañía, Argentina, Argentina Sono Film, 1940.

Zabalía, Alberto de, Cuando florezca el naranjo, Argentina, Cinepa, 1943. 